\title{
O INTELLECTUS COM OS PÉS NA RES - EXTERNISMO E O PONTO DE PARTIDA DA JUSTI- FICAC̣ÃO
}

\section{Hilan Bensusan (UnB)}

hilanb@unb.br

\author{
an jedem Wort \\ hängen tausend Lügen \\ an jeder Lüge \\ hängen tausend Wahrheiten \\ (Dieter Roos)
}

Resumo: a imagem de que restrições do mundo às nossas crenças e enunciados não são internas ao pensamento parece motivar a separação entre verdades de razão e verdades de fato. Esta separação parece ser crucial para entendermos argumentos em favor de certas versões de externismo. Neste texto, depois de considerar como pode ser feita a separação entre verdades de fato e verdades de razão, apresento uma distinção entre duas formas de externismo e defendo uma delas. Termino recomendando uma específica abordagem, holista e externalista, da relação entre nossos pensamentos e o mundo.

Palavras-Chave: verdade como adequação, questões de fato, externismos, pensamento

I Pensamento, Liberdade e Adequatio Intellectus ad Rem

Uma concepção tradicional do que são pensamentos ou enunciados verdadeiros -facilmente entendida como tributária da idéia de que a verdade é alguma forma de adequatio intellec- 
tus ad rem - entende que tais pensamentos ou enunciados são, de alguma forma, produtos do constrangimento do mundo sobre nosso intelecto que, sem este constrangimento, atuaria em completa soberania. Pensamentos ou enunciados verdadeiros são como que limites na nossa liberdade intelectual: o mundo nos obriga a pensar de uma maneira ou de outra. Esta concepção sugere a imagem de que nossa vida mental ela mesma não depende de como o mundo é; a verdade é imposta desde fora pela coisa à qual o intelecto procura - ou, por alguma razão ou interesse, precisa - se adequar. Uma concepção assim faz da verdade um elemento originado fora das fronteiras do funcionamento habitual do nosso pensamento e, portanto, como um parâmetro externo para o pensamento, como algo que afeta o pensamento desde fora dele.

Esta maneira de entender a conexão entre pensamento e verdade parece menos plausível quando tratamos de pensamentos ou enunciados que pareçam ser de alguma forma conceitualmente (ou logicamente) verdadeiros. No caso de pensamentos ou enunciados que são verdadeiros em função de sua própria forma e com independência de qualquer consulta ao mundo - verdadeiros em função de seu significado apenas e com o valor de verdade determinável sem consulta ao mundo (por exemplo, sem apelo à experiência) - a verdade parece emergir de dentro da esfera do pensamento e o mundo, fora das nossas operações mentais, não teria qualquer papel. Podemos até dizer que, neste caso, o mundo é que teria, de alguma forma, que se conformar aos nossos pensamentos e enunciados verdadeiros. Nós impomos ao mundo, em certo sentido, condições de inteligibilidade. No caso deste tipo de verdades, como no primeiro caso, contudo, temos uma imagem da esfera mental como sendo alheia ao mundo no seguinte sentido: a esfera mental é soberana e auto-contida pois podemos concebê-la sem qualquer apelo ao mundo. $\mathrm{O}$ pensamento não carrega dentro de si a necessidade de satisfazer o mundo - de ser verdadeiro - e nem garante por si só que o mundo poderá satis- 
fazê-lo - ou seja, que o mundo seja inteligível. $\mathrm{O}$ pensamento emerge assim como sendo ele mesmo independente tanto da verdade de seus conteúdos quanto da inteligibilidade do mundo. Temos aqui uma esfera mental alheia ao mundo onde o pensamento acontece e que é soberana enquanto não buscar verdades sobre o mundo.

Esta imagem da relação entre pensamento e mundo a entende como uma relação externa entre dois ingredientes: um ingrediente de pensamento (e enunciação) e um ingrediente de fazedores de verdade (truth-makers). Estes dois ingredientes invocam a imagem que McDOWELL (1995) apresenta sob o nome de uma concepção híbrida do conhecimento: o conhecimento requer razões e, portanto, um esforço do pensamento, mas também a colaboração do mundo permite que o intelecto fique adequado à coisa; em nossos termos, sem o insumo vindo do mundo, nosso pensamento soberano jamais alcançaria verdades e, portanto, conhecimentos. O conhecimento (acerca do mundo) não pode ser resultado do pensamento sem alguma contribuição externa. A verdade, pelo menos acerca dos enunciados e pensamentos sobre o mundo, é alguma coisa que requer um insumo externo para constranger ou, por meio de algum favor, colaborar com o nosso esforço de pensamento. Nesta imagem, o mundo deve poder colocar restrições ao nosso pensamento; se estas restrições não forem possíveis, nosso pensamento não terá contato algum com o mundo. A restrição aparece como a única possível forma de contato.

Podemos ter a impressão de que a noção mesma de uma adequatio intellectus ad rem invoca a idéia de que nossa soberania é limitada pelas verdades acerca do mundo. Parece que a noção invoca uma relação externa entre o mundo que torna algum enunciado ou pensamento verdadeiro de um lado e o intellectus que o formula do outro. O pensamento é entendido como um movimento de conteúdos alheio às sanções do mundo; as sanções aparecem apenas crivando o pensamento (ou o enunciado) com uma marca de verdade (ou falsidade). Fica 
parecendo então que este diagnóstico da origem da idéia de verdade como adequatio intellectus ad rem se compromete com a imagem de que o pensamento é ele mesmo independente tanto de se seus conteúdos estarem adequados ao mundo quanto de se o mundo é ele mesmo inteligível ao nosso pensamento. $\mathrm{O}$ contato com o mundo por meio de uma restrição ao pensamento produz verdades acerca do mundo e as verdades conceptuais, internas ao pensamento, são, por si só, alheias a como é o mundo. Surge daqui então a distinção entre verdades de razão e verdades de fato. As primeiras são internas ao pensamento e muitas vezes são apresentadas como propriedades do pensamento ele mesmo. A distinção ela mesma surge da maneira de entender o pensamento segundo o qual ele atua com independência de qualquer conhecimento acerca do mundo.

A diferença entre verdades de fato e verdades de razão pode ser entendida pelo menos de quatro maneiras. Estas quatro maneiras de entender a diferença entre verdades estão comprometidas com algumas maneiras de entender o contraste entre o que é interno e o que é externo ao nosso pensamento. A diferença pode ser entendida como (1) a diferença entre as verdades lógicas e as demais verdades (se eu penso que a neve é branca não posso pensar que a neve, ao mesmo tempo, não é branca e, para saber isto, não preciso saber de nenhuma verdade acerca do mundo), pode ser (2) a diferença entre verdades semânticas e as demais verdades (se eu penso que a neve é branca não posso pensar que a neve, ao mesmo tempo, é de alguma outra cor e para saber isto basta que eu conheça o significado das palavras e, é claro, isto não requer que eu saiba nada acerca do mundo), pode ser (3) a diferença entre verdades que dizem respeito à minha vida mental apenas e as demais verdades (neste caso, tenho acesso imediato a verdades acerca das minhas crenças e desejos e, para isto, não preciso saber nada acerca do mundo) ou pode ser (4) a diferença entre verdades acerca da justificação das crenças e as demais verdades (a justificação é alguma coisa que eu conheço desde dentro, não 
preciso consultar o mundo). Nos quatro casos assumimos que o acesso à vida mental não é ainda um acesso a parte alguma do mundo. No primeiro, esta premissa se associa à distinção entre verdades lógicas e as demais verdades: a idéia de que podemos aprender a manipular logicamente conteúdos sem saber nada acerca do mundo. No segundo, a premissa se associa a uma distinção entre verdades analíticas, independente de qualquer conhecimento do mundo, e verdades sintéticas. No terceiro caso, temos a distinção de verdades acerca de minha vida mental e outras verdades; temos uma esfera de verdades sobre aquilo que parece a mim indiferente ao resto do mundo - ou seja, temos um conhecimento de verdades de fato sobre uma esfera que não informa nada acerca de como todo o resto do mundo é. No quarto caso, a justificação pertence ao escopo do que é interno ao alcance de nossas mentes: o espaço das razões funciona com uma independência de como o mundo é e, assim, podemos conhecer razões indiferentes às verdades acerca do mundo. Em todos os casos, evocamos a separação entre liberdade de pensamento de um lado e verdades acerca do mundo de outro.

O primeiro caso requer que possamos manipular conteúdos sem saber nada acerca do mundo; sabemos a priori o que significam algumas expressões lógicas e com isto há muitas possibilidades pensáveis entre as tautologias e as falsidades lógicas - estas possibilidades são nossa liberdade de pensamento enquanto não precisamos tomar em consideração as verdades acerca do mundo. Estas possibilidades são conteúdos pensáveis, supostamente inteligíveis sem apelo ao mundo. Trata-se aqui de uma concepção das verdades conhecidas a priori de acordo com a qual elas são convenções que não dizem respeito ao mundo, mas apenas a como vamos enquadrá-lo; postulados que dão conteúdo à experiência sensível. Pensamentos e enunciados empíricos terão que ter a forma permitida por esta estrutura lógica. Para que possamos de algum modo entender esta separação entre forma e conteúdo empírico como um con- 
traste entre soberania do pensamento e as restrições do mundo temos que assumir que a forma ou a estrutura lógica - expressa por meio do significado de certas expressões - podem ser adquiridas sem nenhum conhecimento do mundo. Podemos considerar aqui que o mundo pode não estar de acordo com o que julgamos necessário para pensar; neste caso o mundo é ininteligível - neste caso, o mundo poderia ser visto como ininteligível. Verdades lógicas são por vezes vistas como convenções através das quais vemos o mundo - o mundo pode ser concebido fora do registro destas convenções. Em certa medida, Quine e Carnap concordariam que a aquisição desta estrutura não é mais do que a aquisição de um conjunto articulado de convenções, mas Carnap insinua que a escolha de convenções é em grande medida indiferente à verdade empírica. Quine, no espírito dos últimos parágrafos dos Dois Dogmas, insistiria que a aquisição dessas convenções determina o que tomamos como verdades acerca do mundo e não podem ser separadas delas - nossa visão de mundo é um tecido cinzento: fios brancos são verdades empíricas, fios negros convenções (QUINE, 1960). Uma tal posição ofereceria já uma aproximação entre os conteúdos de pensamento verdadeiros e a inteligibilidade do mundo.

O segundo caso associa o contraste entre nossa soberania e as restrições do mundo diretamente com a distinção entre juízos analíticos e sintéticos. Nenhum conhecimento do mundo seria necessário para conhecermos o significado das palavras. Aqui nosso contraste precisa que as verdades por meio do significado sejam inteligíveis separadas das verdades sintéticas e, assim, depende da plausibilidade do primeiro dogma do empirismo. Os significados das expressões dão conteúdo aos nossos pensamentos e a idéia é que, mesmo se para termos conhecimento semântico precisamos de uma comunidade com um critério de correção, não precisamos ainda assumir nada acerca do mundo; pensamos com conteúdo, uma vez que nossas expressões têm significado, e podemos pensar o que quisermos, 
restrições à nossa soberania aparecem quando o mundo determina que um certo pensamento ou enunciado em forma de juízo sintético é verdadeiro. Aqui o conhecimento dos significados é a priori e indiferente ao que é o caso no mundo. Estamos, portanto, assumindo que o conhecimento de significados não requer nenhuma investigação ou suposição sobre o mundo e, portanto, podemos distinguir nossos pensamentos acerca do mundo e nosso conhecimento do significado das palavras. Assim, podemos colocar em cheque todo o nosso conhecimento do mundo externo e, ainda assim, dar sentido aos nossos enunciados e pensamentos.

A possibilidade de que seja inteligível que o conhecimento do mundo possa ser posto em cheque é uma conseqüência da idéia de que verdades sobre o mundo limitam nossa soberania: há a possibilidade de que todos os nossos pensamentos sobre o mundo sejam falsos uma vez que os conteúdos de nossos pensamentos são eles mesmos indiferentes ao mundo. No terceiro caso, nossos pensamentos são formados e entendidos sem qualquer apelo ao mundo. Podemos, portanto, formular uma dúvida global acerca de uma visão de mundo e, ainda assim, entendê-la. O terceiro caso é o mais próximo das formulações típicas do dualismo cartesiano entre pensamento e mundo: de nossa vida mental podemos ter certeza sem precisar conhecer qualquer outra parte do mundo - todo o resto pode ser colocado entre parêntesis ${ }^{1}$. O conhecimento de primeira pessoa é freqüentemente entendido como sendo a priori, como não requerendo nenhuma investigação ou suposição de como o mundo é (BURGE, 1988; McKINSEY, 1991). O contraste é entre as verdades conhecidas por introspecção - nossa vida mental observando nossa própria vida mental - e o resto do mundo que pode ser de qualquer jeito (ou de nenhum jeito), uma vez que nossos pensamentos aparecem com independência dele. A separação entre o espaço das crenças e o resto do mundo não precisa supor que as crenças se movem em um domínio privado, elas podem depender intrinsecamente de po- 
derem ser difundidas e controladas por uma comunidade ${ }^{2}$. $\mathrm{O}$ terceiro caso supõe o segundo uma vez que nossos conteúdos mentais precisam ser inteligíveis sem recurso ao mundo para que nossas crenças possam ser compreendidas sem apelo a ele. Nossa vida mental seria em grande medida mantida tal como ela é se removêssemos o mundo; o mundo apenas restringe os pensamentos que podemos ter e o faz desde fora.

No quarto caso também a justificação de nossas crenças é alheia às verdades do mundo; também as razões para pensarmos como pensamos estão do lado do intellectus na dualidade. Neste caso, a verdade é entendida como inteiramente independente da justificação - uma forte transcendência da verdade que alimenta a adequatio. Nos termos de McDOWELL (1995), quando obtemos uma verdade, o mundo nos faz um favor. É claro que pode ser que nos enganemos sempre com respeito ao que é verdade, pois nos baseamos sempre em nossas melhores razões; o mundo fica desligado de nosso pensamento e a radical inacessibilidade das verdades acerca do mundo se torna inteligível. Neste quarto caso, a justificação é acessível, mas ela não oferece nenhuma ponte para o conhecimento do mundo. Aqui a justificação fica inteiramente separada da verdade e exemplos como os apresentados por Gettier tornam-se freqüentes e mesmo inescapáveis: nunca há um elo que não seja casual entre a verdade e nossas boas razões - crenças justificadas são verdadeiras apenas por coincidência. Este caso se aproxima do idealismo transcendental de Kant se entendemos que a coisa-sem-si pode constituir um truth-maker ${ }^{3}$. Aparece aqui a imagem apresentada e criticada por McDOWELL (1995): um espaço lógico das razões internalizado, limitado ao escopo do pensamento e alheio ao mundo. Aqui parece difícil entender como as verdades acerca do mundo podem restringir a soberania de nossas atividades mentais uma vez que elas surgem como inalcançáveis e que nossas razões podem sempre falhar em capturá-las.

Nos quatro casos há uma separação entre intellectus e o lócus das verdades acerca do mundo. A res pode afetar desde 
fora nosso pensamento porque este não é constituído por ela; podemos em alguma medida pensar - e produzir enunciados, atribuir conteúdo à vida mental de outras pessoas, manter algumas crenças e talvez até demandar e oferecer razões - com indiferença ao mundo. Este é entendido como estando retirado, alheio ao nosso esforço de pensar e, portanto, adicionado ao pensamento como um parâmetro externo depois que a estrutura do nosso pensamento já está constituída. Nossa liberdade de pensamento - nossa se nossos pensamentos não puderem ser itens com conteúdo por meio apenas de artifícios privados - contrasta com aquilo que não é um produto da nossa soberania: o mundo. O intellectus, restrito ou não pela fricção interna da comunidade, atua com independência de qualquer conhecimento sobre o mundo; nós, aqueles que pensam e que influenciam no pensamento dos que pensam, temos ali o nosso espaço de soberania.

\section{Conhecimento e Visão de Primeira PessoA}

A separação entre pensamento e verdades acerca do mundo - entre nossa vida mental e os fatos e objetos acerca dos quais nós pensamos - nos deixa em perigo de não encontrar força e legitimidade suficientes nas restrições que o mundo, desde fora, pode produzir nos nossos pensamentos. Podemos terminar confinados entre nossos pensamentos e, do ponto de vista de quem pensa, o mundo pode ficar inalcançável. Este confinamento não ocorre se nosso pensamento e nossa vida mental de alguma maneira demandam verdades acerca do mundo. De um ponto de vista bastante abstrato, esta pode ser a motivação para o recente interesse por posições externistas acerca do pensamento e da justificação. DAVIDSON, por exemplo, sentencia que "a única alternativa ao subjetivismo é o externismo, uma visão que torna a conexão entre pensamento e mundo intrínseco ao invés de extrínsecos - uma conexão não inferida, construída ou descoberta, mas presente desde o 
começo"4 (2001, p. 2).

Ao rompermos, no entanto, com a separação entre o lócus das verdades acerca do mundo e nossa vida mental, podemos ter a impressão de que estamos ferindo a distinção entre conhecimentos empíricos de um lado e conhecimento a priori de outro. Ao colocarmos em questão a distinção entre verdades de razão e verdades de fato estamos invocando problemas com respeito à idéia de algum conhecimento a priori. Assim McKINSEY (1991), por exemplo, considera que se o conteúdo de nossos pensamentos depende de suposições acerca do mundo - responde já a verdades acerca do mundo - não podemos ter um conhecimento privilegiado de nossos próprios estados mentais. Esta opinião é derivada do entendimento de que um conhecimento privilegiado de nossos próprios estados mentais requer que nós os conheçamos a priori - que conheçamos a priori julgamentos sobre todos os nossos próprios estados mentais. E, de fato, não podemos falar de conhecimento a priori de nossos estados mentais se para isto precisamos fazer uso para algum conhecimento de como o mundo é e, portanto, de um conhecimento a posteriori. Ou seja, o intellectus já precisa de alguma maneira de verdades acerca do mundo para obter verdades acerca de si mesmo. Se o intellectus não é uma variável independente do mundo, parece que não podemos mais separar o que sabemos a priori do nosso conhecimento de verdades acerca do mundo ${ }^{5}$. A formulação da dúvida acerca de fatos do mundo (por exemplo, quanto a se o futuro se espelha relevantemente no passado) parece requerer para a sua formulação alguma verdade acerca do mundo (por exemplo, acerca dos relógios físicos) (Cf. BENSUSAN, 2004). Não parece que haja espaço para algum conhecimento que, necessitando apenas de pensamento, não requeira nenhum conhecimento acerca do mundo. Parece que uma ponte segura entre mente e mundo não é compatível com a distinção entre conhecimentos $a$ priori e conhecimentos obtidos em contato com o mundo se entendemos a distinção como co-extensiva àquela entre conhe- 
cimentos indiferentes ao mundo e conhecimentos que requerem uma consulta ao mundo que demande, em algum sentido, mais do que a mera atividade de pensar.

No entanto, nem todo modelo de nossa vida mental como dependente do mundo externo abre mão desta distinção. Tentarei nesta seção esboçar um modelo da nossa vida mental como dependente do mundo que permita que façamos justiça a alguns elementos que orientam a distinção entre conhecimentos empíricos e conhecimentos a priori.

Há dois modelos do pensamento como sendo uma variável dependente do mundo. $\mathrm{O}$ primeiro deles consiste em sustentar que o intellectus é uma variável dependente da res no sentido de que a nossa vida mental tem como condição de possibilidade um estado de coisas no mundo. Assim, neste modelo insistimos que o pensamento depende do cérebro para acontecer ainda que possamos pensar sem sabermos nada acerca do cérebro. Ou seja, do ponto de vista da experiência de pensamento, podemos duvidar da necessidade de cérebros para o pensamento; a dúvida é possível: a dependência entre intellectus e res é alguma coisa que uma teoria sobre o mundo (por exemplo, uma teoria científica) pode mostrar. Neste primeiro modelo, qualquer de nossos estados mentais pode depender do mundo - estamos em estados mentais diferentes diante de $\mathrm{H}_{2} \mathrm{O}$ e diante de $\mathrm{XYZ}$ - e, ainda assim, do ponto de vista de quem pensa ou usa os termos, podemos não distinguir entre os diferentes estados mentais em que nos encontramos. O elo com o mundo é freqüentemente concebido em termos de uma conexão semântica entre um termo e uma parte do mundo: por exemplo, a microestrutura física da água determina o significado do termo "água"; o conteúdo se transforma quando a microestrutura se transforma mesmo que não saibamos nada sobre a microestrutura da água - e mesmo que sejamos abduzidos para a Terra Gêmea onde a microestrutura da água é XYZ, mas todas as nossas demais crenças verdadeiras sobre a água seguem sendo verdadeiras. Analogamente, podemos não saber 
nada sobre o cérebro que torna possível que pensemos. A conexão entre mente e mundo não envolve nenhum elemento acessível à experiência de quem pensa. Neste contexto, podemos experimentar a tentação de conceber que nossos pensamentos não são ainda nem sobre $\mathrm{H}_{2} \mathrm{O}$ nem sobre $\mathrm{XYZ}$ - podemos pensar em um conteúdo estreito (FODOR, 1987) ou em um máximo fator comum (McDOWELL, 1998). Parece que neste modelo nada impede que o nosso pensamento se limite a estes elementos que são neutros com respeito ao mundo.

Um segundo modelo conceberia que o intellectus não pode existir sem algum conhecimento da res, nosso pensamento não seria possível se não soubéssemos já alguma coisa sobre o mundo (je pense donc je sais). O intellectus aqui é uma variável que requer um conhecimento da res: não há pensamento sem que haja conhecimento - nossos conteúdos são determinados pelo nosso esforço em manter crenças verdadeiras com base no conhecimento que possuímos. Apenas podemos determinar o que alguém está pensando dentro de um plano de fundo de verdades que tornam possível que objetos e fatos cognoscíveis possam estar sendo pensados. $\mathrm{O}$ intellectus depende do que consideramos ser conhecimento - e se não podemos dar sentido ao erro global, o intellectus depende de algum conhecimento da res. DAVIDSON (2001) argumenta que quem pensa precisa de conhecimentos de três tipos: acerca do mundo, acerca de si mesmo e acerca dos demais membros da comunidade de pensadores. A res precisa ser pelo menos parcialmente conhecida para que comecemos um processo de pensamento. De fato, a individuação de elementos da res para um confronto com o que pensamos requer já que sejamos capazes de algum exercício de predicação que precisa estar apoiado em algum conhecimento. O conhecimento é um ponto de partida e não apenas um ponto de chegada do pensamento; movemo-nos de verdades em direção a verdades e a adequação não pode ser entre dois itens desprovidos de verdade. A verdade aparece então 
como substrato do pensamento e não como seu objetivo; como as ruas que conduzem o pensamento e já não como o sinal que restringe o seu trânsito.

O segundo modelo, em certo sentido, abrange alguns elementos do primeiro: para que o conhecimento da res seja condição necessária para o funcionamento do intellectus, é preciso que verdades acerca da res sejam condição necessária para o funcionamento do intellectus - se há alguma conexão estreita como é razoável supor entre conhecimento e verdade. Por outro lado, o primeiro modelo pode ser insuficiente para conectar nosso pensamento ao mundo: podemos não ter parte alguma do mundo limitando nosso pensamento, ainda que ele esteja presente e tornando possível nosso pensamento - conectado causalmente com ele. No primeiro modelo, sempre há um refúgio de intellectus alheio à res no escopo dos conteúdos estreitos. McKINSEY (1991) observa que se o elo entre o nosso pensamento e o mundo é simplesmente um elo de necessidade metafísica - e não de conhecimento - a idéia de conhecimento a priori do que é mental (por exemplo, conhecimento do conteúdo de nossos conceitos) ainda pode ser preservada (tal como, de fato, sugere a tentativa de BURGE (1979) de preservar o privilégio do conhecimento de primeira pessoa). Se o elo entre pensamento e mundo não envolve conhecimento, o primeiro ainda pode ser independente do mundo: se o elo não é tal que o conteúdo do nosso pensamento do ponto de vista de alguém em que ocorre o pensamento não requer a existência de alguma coisa para além dele. Se, de alguma maneira, pudermos preservar a idéia de um conhecimento privilegiado de nossa vida mental que seja a priori, estaremos, de fato, preservando a idéia de que o intellectus pode se constituir independente de qualquer outra parte do mundo e indiferente a qualquer verdade sobre o mundo. Em contraste, do ponto de vista do segundo modelo, os conhecimentos a priori só são possíveis se, de alguma maneira, eles puderem ser conhecimentos acerca do que 
chamamos verdades de fato: conhecimentos acerca do mundo. Ou seja, se pudermos conhecer, como condição de possibilidade de nosso pensamento, certos fatos acerca do mundo.

O segundo modelo pode abrigar uma concepção dos conhecimentos a priori segundo a qual estes são conhecimentos acerca do mundo. Há aqui uma semelhança com a idéia de juízos sintéticos a priori: trata-se de conhecimentos acerca do mundo que são as condições de possibilidade para que tenhamos conhecimentos empíricos - condições de possibilidade para que possamos ter pensamentos. Há algumas diferenças importantes com a maneira que Kant recomenda que entendamos estes juízos. De acordo com esta concepção do conhecimento a priori, alguns conhecimentos são supostos para que possamos começar a pensar (e, eventualmente, fazer juízos empíricos), porém não há nenhum juízo em particular que possa ser considerado como cognoscível a priori: em princípio, qualquer juízo pode ser conhecido a priori, se bem que algum conhecimento é necessário para que o intellectus atue. Uma doutrina assim do conhecimento a priori exibe os elos entre conhecimento de verdades acerca do mundo de um lado e nossa capacidade de pensar do outro: não há pensamento sem algum conhecimento e, apenas neste sentido, chamamos este conhecimento de a priori - condição necessária para o pensamento e para qualquer experiência. O tema da prioridade, contudo, pode gerar um incômodo. Podemos ter a impressão de que teríamos que obter conhecimentos a priori antes de sermos capazes de nos engajarmos em exercícios conceituais e, portanto, estes conhecimentos seriam de uma natureza não-conceitual e, talvez, até mesmo inatos. Penso que não precisa ser assim. A prioridade em questão seria apenas uma prioridade na conexão lógica que poderia ser expressa apenas em termos de condições necessárias para o pensamento. Algum conhecimento é condição necessária para que haja pensamento (e experiência etc.) e, em seguida, mais conhecimento. $\mathrm{E}$, de fato, parece razoável que o conhecimento requeira capacidades conceituais uma vez que o 
limite desta maneira alternativa de entender os conhecimentos a priori é que conhecer sempre requer algum pensamento e vice-versa - a imagem de WITTGENSTEIN (1969, § 141) freqüentemente evocada para trazer à tona uma massa crítica que se constitui em partes: light dawns gradually on the whole. A distinção entre conhecimentos a priori e os demais conhecimentos é, em parte, apenas uma questão de acesso: os demais conhecimentos são obtidos quando o pensamento já pode ser reconhecido como tal; quando podemos identificar - interpretar - o pensamento.

De acordo com este segundo modelo, a justificação de nossas crenças e a construção de conhecimento empírico requer que tenhamos já algum conhecimento sobre o mundo. Parece que a imagem que emerge é aquela em que a justificação tem como ponto de partida algum conhecimento - ela não pode começar de um ponto onde ainda não sabemos nada pois teríamos então que obtê-la por meio de uma restrição externa à supostamente completa soberania do nosso processo de pensamento. Este segundo modelo, portanto, apresenta uma situação em que uma argumentação cética não pode colocar em questão nossa capacidade de ver a soberania do intellectus restringida por algo externo a ele. A concepção do ponto de partida da justificação (e do conhecimento empírico) que surge deste modelo é em alguma medida kantiana: precisamos já saber alguma coisa acerca do mundo antes de começarmos a fazer juízos empíricos. Uma diferença importante, entretanto, é que aqui o ponto de partida não é nenhum conjunto específico de juízos - é preciso que a justificação comece de alguma parte; ela não pode começar de um ponto desprovido de qualquer contato com o mundo e, no entanto, ela pode começar em diferentes pontos de contato com o mundo. A justificação requer conhecimento a priori, mas este conhecimento pode ter qualquer conteúdo.

É interessante notar que este segundo modelo requer que tenhamos alguns conhecimentos (não-especificáveis) a 
priori e, ao mesmo tempo, rejeita qualquer tentativa de distinguir verdades de razão de verdades de fato. A idéia é que o conhecimento das verdades de fato (verdades não-lógicas, verdades sintéticas, verdades sobre o que é alheio à minha própria mente ou verdades que não dizem respeito diretamente à justificação de nossas crenças) afeta o acesso e a inteligibilidade das verdades de razão de tal modo que não há o que assegure um escopo específico às verdades de razão; um escopo alheio ao (nosso conhecimento de) como o mundo é. Uma maneira de entender este segundo modelo é insistir que o elo entre nossos pensamentos e o mundo deve ser um elo desde dentro, acessível desde nossos pensamentos. A autoridade do mundo sobre o intellectus deve passar pelo crivo de uma Anerkennung ${ }^{6}$; sem isto nossos conteúdos e nossas justificações poderiam ser alheias a tudo o que nos parece que pensamos. O elo com os conhecimentos acerca do mundo parece requerer uma autoridade de primeira pessoa sobre o que pensamos e sobre o que conhecemos: pelo menos algum conhecimento do mundo nós devemos ter para que o intellectus não seja alheio às verdades de fato. Nossas mentes - nossos conteúdos mentais, nossas justificações - não podem ser inteiramente opacos ao nosso conhecimento; se assim o forem, estaremos abrindo as portas para um refúgio na indiferença do mundo constituído pelo escopo dos conteúdos estreitos.

A estes dois modelos correspondem duas formas de externismo. Na primeira destas formas, nosso pensamento tem conteúdos determinados pelo ambiente (físico ou social) à nossa volta, mas esta determinação não é acessível a quem está pensando. Assim, no caso de um externismo social ${ }^{7}$, nosso pensamento depende de outras pessoas estarem presentes, pois elas nos tornam capazes de fazer julgamentos, pois inserem em nós uma noção de correção (e de erro). Esta dependência, no entanto, é em algum sentido externa ao pensamento como percebido do ponto de vista de primeira pessoa: uma vez que a idéia de erro é instituída pela comunidade, podemos come- 
çar a pensar sem nenhuma consciência de que a comunidade instaurou em nós - ou está constantemente mantendo em nós - a capacidade de fazer julgamentos. No caso do externismo perceptual $^{8}$, as relações causais entre o ambiente e quem pensa podem também passar desapercebidas a quem pensa ou percebe; também neste caso o vínculo entre pensamento e mundo pode estar presente sem que esteja disponível à primeira pessoa. Na nossa segunda forma de externismo, o mundo está intrinsecamente conectado às nossas crenças; não é alguma coisa externa à totalidade delas se bem que cada uma de nossas crenças possa estar incorreta. $\mathrm{O}$ mundo está aberto a nós desde dentro dos nossos pensamentos: nossos pensamentos requerem conhecimento e o conhecimento é já uma cola que vincula nossa vida mental - em particular nossas crenças - com o mundo que está disponível para nós desde o começo da nossa atividade de pensamento. $O$ pensamento aparece sempre associado a um conjunto de conhecimentos sobre o mundo - ainda que não precise estar associado a nenhum conhecimento sobre o mundo em particular. Penso, logo sei - alguma coisa tenho que saber para que eu comece a ter pensamentos: não há uma estrutura conceitual que eu possa adquirir e que seja ao mesmo tempo inteiramente ignorante acerca de como são as coisas no mundo. Acesso àquilo que permite o pensamento - por exemplo, a uma linguagem pública - é também acesso a algum conhecimento sobre o mundo.

Como determinar um conteúdo de pensamento? De acordo com o segundo modelo (e a segunda forma de externismo), não podemos apelar apenas para partes do mundo: não podemos atribuir conteúdos sem nenhum apelo a uma visão de primeira pessoa. Não podemos, por exemplo, desde fora de um cérebro em uma cuba, determinar que os pensamentos de um cérebro assim só poderiam ser verdadeiros acerca dos fios conectados ao cérebro - poderíamos ser motivados a pensar assim por observações de DAVIDSON (2001) de que aquilo que causa sistematicamente os nossos pensamentos são tam- 
bém os conteúdos destes pensamentos (RORTY, 1986). Uma atribuição de conteúdo assim faz com que possamos estar sistematicamente enganados sobre do que tratam nossas crenças verdadeiras - ainda que a maioria de nossas crenças sejam verdadeiras ${ }^{9}$. De acordo com o nosso segundo modelo, uma atribuição assim seria feita a partir de fora do pensamento, com independência da visão de primeira pessoa - teríamos o pensamento e o mundo inteiramente desconectados: o pensamento (de primeira pessoa) sobre árvores e pessoas, o mundo de fios. Ainda com respeito a este exemplo, a idéia mesma de um cérebro em uma cuba isolado de elementos externos capazes de constituir a base de conhecimento para que haja intellectus é ininteligivel: se eu for um tal cérebro jamais terei condições de dar sentido ao confronto entre o que penso que sei e os fios - meus conhecimentos jamais permitiriam que um confronto assim fosse inteligível.

Este segundo modelo se encontra expresso em algumas idéias de Davidson. O pensamento, neste modelo, parece requerer sempre uma massa crítica capaz de envolver um conhecimento acerca do mundo de modo a que o confronto seja possível. O confronto é possível se o conteúdo pode ser produto de uma negociação entre o mundo e as visões de primeira e terceira pessoas: a atribuição de conteúdos deve ser feita também com base no que é acessível à primeira pessoa, à pessoa que pensa. Os conhecimentos - desde o ponto de vista de quem os tem - são os únicos parâmetros para determinar sobre o que pensamos e para enquadrar nossos pensamentos em uma situação em que eles possam ser confrontados com o mundo. Este segundo modelo parece ter que atribuir conteúdos a uma massa crítica de pensamentos de modo que um termo não possa ter seu conteúdo refém apenas de um item do mundo - por exemplo, da microestrutura da água. Parece que a determinação do conteúdo não se baseia em juízos capazes, sozinhos, de exprimir a conexão com o mundo - como "água é $\mathrm{H}_{2} \mathrm{O}$ ". No primeiro modelo, podemos ter a situação em que o 
conteúdo de nossos pensamentos se transforma se, sem saber, somos abduzidos para a Terra Gêmea. Podemos então perder a capacidade de memória preservativa e pensar em diferentes partes do mundo ao longo de uma cadeia de pensamento ou de uma inferência sem nos darmos conta. No segundo modelo, uma única crença tornada falsa não é suficiente para demolir o conteúdo em questão; ainda nos apoiamos em outras crenças ainda verdadeiras para continuar pensando na água depois da abdução ${ }^{10}$. Ou seja, parece que este modelo encoraja uma dose de holismo acerca do conteúdo dos pensamentos: podemos nos virar se apenas alguns pensamentos tornarem-se falsos por meio de alguma transformação no ambiente.

O caso seria diferente - e mais grave - se nosso cérebro fosse transportado para uma cuba com fios que simulassem o resto do mundo. Aqui, parece que muitos pensamentos se tornaram falsos devido à transformação do ambiente. Teremos que ter, no entanto, alguns pensamentos compartilhados para que haja a possibilidade de confronto. $\mathrm{O}$ conteúdo de pensamento, que, como Davidson muitas vezes enfatizou, teria que resultar de um esforço de interpretação, estaria baseado em crenças compartilhadas dentro e fora da cuba - "água" estaria presente em diversas crenças que continuam verdadeiras. Neste modelo, não há um juízo - nem sequer um juízo assentido por quem pensa acerca do que significa "água" - que aloque o conteúdo de um termo; o conteúdo emerge do que podemos em cada caso estabelecer como conhecimento partilhado do mundo: dentre os demais pensamentos acerca da água etc. A introdução de um intérprete de fora da cuba é a única maneira de podermos eventualmente introduzir confronto no que diz respeito aos pensamentos acerca dos fios (ou de que há árvores e não meros fios). Este intérprete pode eventualmente determinar sobre o que o cérebro estaria pensando. Aqui também o expurgo de elementos atomistas nos ajuda a entender em que sentido há pensamento e, neste quadro, determinar seu conteúdo. Esta determinação depende de que outros pensa- 
mentos presentes formem um plano de fundo contra o qual o confronto se torne inteligível.

\section{Gargalos e o Contato Holístico Entre Mente e Mundo}

O modelo de conexão entre pensamento e mundo apresentado aqui, onde não há um espaço de soberania alheio ao mundo, conecta pensamento e mundo por meio da necessidade de que haja conhecimento para que ocorra o pensamento. A interpretação depende de conhecimentos compartilhados e, sem estes conhecimentos, não podemos sequer fazer sentido de um confronto entre intellectus e res ou de uma restrição à nossa soberania proveniente do mundo. Se o modelo segundo o qual o pensamento requer conhecimentos da res for aceito, então o contato entre pensamento e mundo se dá no bojo mesmo de nossa atividade de pensar: a influência do mundo sobre o nosso pensamento se dá no conjunto de nossas crenças. Trata-se de uma concepção do contato entre pensamento e mundo que o entende como espalhado por toda a nossa atividade de pensamento contrastando com a imagem do contato entre pensamento e mundo como sendo uma forma de restrição externa do mundo ao pensamento. $\mathrm{O}$ pensamento, também de acordo com esta concepção, recebe restrição por parte do conhecimento do mundo em cada uma de suas partes - e neste sentido talvez possamos ainda considerar que há um papel para a receptividade, mas não há como isolar em um tecido de espontaneidade e receptividade os fios que sejam pura receptividade - mas estas restrições são internas ao processo mesmo que torna o pensamento inteligível. $\mathrm{O}$ contato com o mundo é garantido pela necessidade de um conhecimento de verdades de fato para que o pensamento seja inteligível. Uma vez que não podemos especificar as verdades de fato (acerca de nós, de nossa comunidade ou do mundo) que estão presentes para que o pensamento seja possível, não é senão em um conjunto de crenças que podemos falar de contato com o mundo. 
Esta doutrina holística do contato entre pensamento e mundo está de acordo com um esquema de argumento contra a inteligibilidade do erro massivo, inspirado em DAVIDSON contra a inteligibilidade do erro global (1974, 1986 e 1991a). Trata-se de um esquema de argumento que também pode nos conduzir ao segundo modelo do qual falei na seção anterior: a inteligibilidade do intellectus requer conhecimento acerca do mundo e um pensamento isolado não é capaz de tornar possível o confronto. $\mathrm{O}$ esquema de argumento fica mais persuasivo se acoplado a uma rejeição da distinção entre verdades de fato e verdades de razão por exemplo na segunda maneira apresentada na primeira seção: a rejeição do primeiro dogma denunciado por Quine (Cf. DAVIDSON, 1991b, p. 195). A idéia do argumento é que, sem um acesso massivo à res, não podemos fazer sentido de qualquer contraste entre nosso pensamento e o mundo e, portanto, não podemos fazer sentido da dúvida global - alguma inteligibilidade requer acesso a alguma verdade. Ninguém pode compreender o que eu digo e discordar de tudo. Além disso, não podemos entender um pensamento que esteja engajado em um erro massivo - não podemos interpretar tal pensamento. $\mathrm{O}$ contraste, ou o confronto, que dá sentido ao erro, só é possível em um plano de fundo de acesso à res. Assim, nosso contato com o mundo é garantido pela interpretabilidade, em uma triangulação, de nossos pensamentos. $\mathrm{O}$ esquema de argumento pode ser apresentado em termos de classes de pensamentos que sejam semanticamente auto-suficientes (SAS); ou seja, que podem ser entendidos sem apelo a nenhum pensamento fora da classe. Vou apresentar o esquema de argumento em termos de contato com o mundo - que pode ser entendido em termos de verdade ou em termos de conhecimento:

I. Um pensamento isolado não pode ser inteligível e nem pode receber um veredicto do mundo. São necessários outros pensamentos para 
dar-lhe conteúdo e tornar o confronto com o mundo possível. Ou seja, uma SAS é sempre formada por mais de um pensamento.

II. O trabalho semântico é igualmente dividido em uma SAS. Ou seja, não existe uma maneira criteriosa de destacar os membros de uma SAS que são responsáveis pelo nosso entendimento de todos os demais pensamentos na SAS.

III. Se uma subclasse suficientemente grande de pensamentos em um SAS não tem contato com o mundo, não podemos estabelecer de que modo poder-se-ia confrontar qualquer outro membro da SAS com o mundo. Portanto, tem que haver contato com o mundo entre os membros de uma SAS - a idéia de que nenhum membro de uma SAS tem contato com o mundo é ininteligível.

IV. Cada pensamento em uma SAS pode não estar em contato com o mundo, mas não é possível que nenhum deles esteja em contato com o mundo. (Só podemos isolar os pensamentos que estão em contato com o mundo se eles formarem uma subclasse SAS; caso contrário seu confronto com o mundo isolado dos demais pensamentos seria ininteligível).

$\mathrm{O}$ esquema funciona se a inferência de I-II-III a IV for válida e I-II-III forem aceitáveis. O esquema procura fazer valer uma concepção holística do contato entre pensamento e mundo onde os pensamentos aparecem em coleções que, se semanticamente auto-suficientes, devem manter algum contato com o mundo. A verdade de alguns dos conteúdos de pensamento e a inteligibilidade (de pelo menos parte) do mundo são conseqüência do argumento. De fato, o argumento formulado em termos de contato pode ser entendido como mostrando que parte dos nossos pensamentos (em uma SAS) deve constituir conhecimento acerca do mundo - e conhecimento supostamente requer verdade ${ }^{11}$. Em contraste com a imagem que en- 
tende contato como restrição do mundo à soberania do pensamento, esta imagem entende que o contato está associado à inteligibilidade mesma do pensamento - ao que torna possível a idéia de que o pensamento pode ser confrontado com o mundo. Se o esquema de argumento funciona, ele pode ser usado para formular argumentos que dissipem alguma forma de ceticismo. O ceticismo global - aquele que alude à possibilidade de que todas as nossas crenças sejam falsas - é um deles se considerarmos que a classe de todas as nossas crenças forma uma SAS - a classe $\mathcal{T}$. Ceticismos menos globais podem ser tratados por argumentos que satisfaçam o esquema se houver SAS que são subclasses da classe de todas as nossas crenças. Se este for o caso, poderemos, por exemplo, apresentar um argumento contra o ceticismo acerca de todas as crenças sobre o futuro: se todas forem falsas, não poderemos mais entender 'amanhã' no juízo "amanhã o sol se levantará". É duvidoso, no entanto, que a classe das nossas crenças sobre o futuro - a classe $F$ - seja semanticamente auto-suficiente. Porém, podemos construir argumentos contra ceticismos localizados, por exemplo acerca da subclasse $C$ se mostrarmos que a extensão da subclasse $C$ não pode ser delimitada se não fizermos uso de alguma crença $c \in$ C. Assim, por exemplo, não podemos delimitar a extensão de $F$ se não fizermos uso para tanto de alguma proposição que determine sobre o que são as crenças de $F$ : alguma proposição como "amanhã é quando os relógios baterem meia-noite", uma proposição que ela mesma é uma crença sobre o futuro que pertence a $F$. Portanto, para delimitarmos a extensão da classe de crenças acerca da qual somos céticos, precisamos fazer uso de uma crença que pertence a esta classe. Não podemos determinar a extensão da classe de crenças acerca da qual somos céticos e, ao mesmo tempo, ter uma atitude cética com respeito a esta classe de crenças. É razoável conjeturar que estes argumentos contra ceticismos - inspirados em uma concepção holística do contato entre o pensamento e o mundo expresso no esquema de argumento I-IV - poderiam ser construídos 
para toda classe de crenças que pudesse ser construída como "a classe de crenças sobre S" para qualquer S. Por outro lado, o esforço para dissipar formas de ceticismo deixa clara a capacidade do esquema de argumento em promover a conexão entre inteligibilidade e acesso a alguma verdade sobre o mundo ${ }^{12}$. $\mathrm{O}$ pensamento emerge como tendo que estar em contato com o mundo - e conhecendo algo sobre o mundo - desde o momento em que pode ser reconhecido como pensamento.

Um contato com o mundo nestas bases estimula uma imagem em que nossos pensamentos se conectam ao mundo apenas por meio de massas críticas de juízos onde o que é asseverado pode ser posto em confronto com alguma res. Esta imagem holística do contato entre pensamento e mundo contrasta com a idéia segundo a qual o contato ocorre em itens específicos de nossa vida mental - por exemplo, detectores de sensação ou crenças básicas ou experiências passivas. Esta imagem postula que o pensamento recebe conteúdo empírico através de uma conexão específica e mantém que sem esta conexão o pensamento fica indiferente ao mundo. De acordo com esta imagem, que chamo da imagem do gargalo ${ }^{13}$, é através de conteúdos específicos que o mundo influencia nosso pensamento. A imagem do gargalo orienta diversas concepções modernas da receptividade; por exemplo, o empirismo clássico que entende que itens sensoriais conectam nosso pensamento a partes do mundo. Trata-se, contudo, de uma imagem que é mais comumente aceita do que o empirismo clássico. Ali, o gargalo procurava ser ao mesmo tempo causal e normativo. Os conteúdos específicos que chegam (ou, antes, são impostos) ao nosso pensamento podem ser conceituais - por exemplo, experiências como exercícios passivos de nossas capacidades conceituais, como na opção que McDOWELL (1994) recomenda. Por outro lado, podemos rejeitar a imagem do gargalo e insistir que o conteúdo empírico pode ser separável de esquemas conceptuais - basta que rejeitemos a capacidade de qualquer contato com o mundo impor conteúdos específicos ao nosso 
pensamento. Uma posição assim é por vezes atribuída a Quine: estímulos sensoriais informam toda a nossa vida mental, mas não através de conteúdos específicos. Sem a alternativa de um contato holístico, o gargalo pode parecer a única alternativa para satisfazer nossa sede de um contato racional com o mundo. $\mathrm{O}$ gargalo vem acoplado de uma imagem do intellectus de acordo com o qual a nossa soberania seria completa se não recebêssemos verdades de fato provenientes do mundo para moldar o que pensamos; sem um gargalo que nos trouxesse estas verdades de fato, estaríamos simplesmente patinando no vazio sem fricção.

A imagem do contato através do gargalo está em acordo com a separação entre verdades de fato e verdades de razão e com a possibilidade de que possamos ficar pensando sem nenhuma conexão com o mundo. $O$ gargalo é uma conexão que transmite conteúdos específicos da res ao intellectus e que permite, por exemplo, entendermos a adequatio como um confronto entre o que há em nosso pensamento e aquilo, especificamente, que o mundo nos conta. Penso que temos razões para rejeitar a imagem do contato através de um gargalo e, com ele, a concepção de nossa soberania que a entende como ilimitada quando ela não recebe restrições externas provenientes do mundo. A imagem do contato holístico - associada à idéia de que o conhecimento do mundo é uma condição necessária para a atividade do intellectus - projeta a imagem de uma soberania que está sempre galgada em algum conhecimento do mundo. O pensamento está sempre às voltas tanto com verdades de fato quanto com nossa autoridade de estabelecer compromissos. Gostaria de propor que a influência do mundo sobre nosso pensamento não precisa ser uma mensagem específica; ela é, antes, um pacote de verdades que permitem que o nosso pensamento comece a se mover. Se nosso pensamento percorre ruas pavimentadas por verdades de fato, temos alguma notícia do mundo quando encontramos as dúvidas e as incorreções, mas, por outro lado, estamos sob o espectro do 
erro (local) mesmo nos melhores momentos de nosso conhecimento. $\mathrm{O}$ intellectus acessa a res desde dentro; está com os pés na res, mesmo quando devaneia soberanamente por entre as suas mais abstratas divagações.

Abstract: The picture of constraints from the world on our statements and beliefs as constrains external to thought itself somehow encourage a distinction between matters of reason and matters of fact. This distinction seems crucial for some arguments in favour of some versions of externalism. In this paper, after considering how the distinction between matters of fact and matters of reason can be made, I put forward and recommend a form of externalism. I finish by articulating a specific holistic and externalist approach to the way our thoughts are constraint by the world.

Key-words: truth as adequatio, matters of fact, externalisms, thought

\section{NOTAS}

1 Para uma análise do internalismo suposto na idéia de epoché, ver BENSUSAN (2004b).

2 Em certo sentido, a separação entre intellectus de um lado e o resto do mundo de outro pode se sustentar mesmo em uma perspectiva que Burge chama de anti-individualista. Um comunitarismo pode vir acoplado com a idéia de que nós, enquanto comunidade, pensamos e nos comunicamos em um meio que é indiferente a como o mundo é. Verdades, pelo menos as verdades de fato, podem jamais ser parte das matérias primas que usamos em nossos pensamentos.

3 H. PUTNAM (1978), na época do seu realismo interno, defendia que nossas justificações eram, em grande medida, alheias ao mundo, porém ele também abraçou uma teoria claramente epistêmica da verdade e, portanto, não tomava partes do mundo como truth-makers. Kant nos serve de melhor exemplo apenas se entendermos que ele concebia a verdade ainda como uma espécie de adequatio intellectus ad rem.

4 "The only alternative to subjectivism is externalism, a view that makes the connection between thought and the world instrinsic rather than extrinsic - a connection 
not inferred, constructed, or discovered, but there from the start".

5 Podemos tentar resistir a esta conclusão entendendo o conhecimento a priori como dependendo de alguma intellectuelle Anschauung e, portanto, sendo um conhecimento do mundo e não apenas do intellectus. Mesmo assim, uma argumentação externalista talvez devesse insistir que os conceitos através dos quais temos esta Anschauung especial são conceitos que dependem do mundo para obter seu conteúdo.

6 Em BENSUSAN (2004a), analiso as relações entre Anerkennung e a o espaço das razões como parte do mundo. O reconhecimento da autoridade do mundo é o que pode tornar a aquisição de crenças acerca do mundo como possível fonte de justificação. De uma maneira geral, o conhecimento do mundo parece requerer um reconhecimento do mundo como autoridade sobre nossos pensamentos (ver, por exemplo, WITTGENSTEIN, 1969, §378). De acordo com este segundo modelo, o reconhecimento da autoridade do mundo sobre nossas crenças é uma condição necessária para haver pensamento - o pensamento é sempre permeável à autoridade do mundo.

$7 \quad$ Veja, por exemplo, BURGE (1979) ou KRIPKE (1982).

8 Veja, por exemplo, PUTNAM (1975) ou BURGE (1988). DAVIDSON (2001), procura por meio da triangulação associar o externalismo perceptual ao social. Como ficará claro mais adiante, parece que este passo não é suficiente para romper com as dificuldades da primeira forma de externismo.

9 O tema aparece também em DAVIDSON (1991a). McDOWELL (1994, p. 17) explora as conseqüências desta atribuição de conteúdo desde uma terceira pessoa para insinuar que não pode haver, na maneira de pensar de Davidson, mais que uma fricção interna entre as crencas indiferente ao mundo.

10 Consideremos uma inferência das premissas 1 e 2 para a conclusão 3: 1. Moléculas de água possuem átomos de hidrogênio; 2. Átomos de hidrogênio têm um único próton; 3. Moléculas de água possuem átomos com um único próton. Se depois da segunda premissa formos ab- 
duzidos e levados para a Terra Gêmea, a inferência será inválida. Neste caso, contudo, podemos simplesmente apelar para premissas que estavam recônditas e que se tornaram falsas sem com isto nos comprometermos com alguma forma de internismo.

11 Não preciso me comprometer aqui com uma definicão de conhecimento. É razoável supor que verdade e conhecimento estão de alguma forma conectados mesmo se não pudermos oferecer uma caracterização do conhecimento em termos de verdade e algum outro elemento.

12 Uma outra forma de argumentação contra ceticismos locais seria mostrar que se $C$ é uma subclasse que não é uma SAS, mas $\mathcal{T}-C$ também não é uma classe SAS, deve haver pelo menos alguma crença verdadeira em $C$. Esta linha de argumentação valeria para alguns ceticismos localizados. Poderíamos apenas endossar um ceticismo acerca de uma classe $C$ qualquer de crenças desde que $\tau-C$ seja uma SAS. Este pode ser o caso se considerarmos a classe de todas as nossas crenças e subtrairmos dela algumas crenças que não afetem a auto-suficiência semântica das crenças restantes. Resta saber que relação de equivalência esta linha de argumentação tem com a argumentação acima.

13 Em Pinedo GARCIA e BENSUSAN (2005) há uma análise mais detalhada da imagem do gargalo. Ali consideramos que tanto McDOWELL (1994) quanto BRANDOM (1994) são ainda reféns da idéia de que o contato entre pensamento e mundo requer que haja algum tipo de gargalo.

\section{REFERENNCIAS}

BENSUSAN, H. O pensamento sem estaca zero (a mentalidade externalista e as razões nossas de cada dia). Kriterion, 110, p. 209-223, 2004a.

Mind and (bracketed) world (Could there be an externalist epoché?). Proceedings of the $27^{\text {th }}$ International Wittgenstein Symposium. Kirchberg, 2004b. 
BRANDOM, R. Making it explicit. Cambridge: Harvard University Press, 1994.

BURGE, T. Individualism and the mental. Midwest Studies in Philosophy, 4, p. 73-122, 1979.

. Individualism and self-knowledge. Journal of Philosophy, LXXXV, 11, 1988.

DAVIDSON, D. On the very idea of a conceptual scheme. Procedings and Addresses of the American Philosophical Association, 47, 1974.

A coherence theory of truth and knowledge. In: LEPORE, Ernest (ed.). Truth and interpretation: perspectives on the philosophy of Donald Davidson. Oxford: Blackwell, 1986, p. 307-19.

. Three varieties of knowledge. In: GRIFFITH, A. Phillips. A. J. Ayer memorial essays; Royal Institute of Philosophy Supplement. 30, Cambridge: UP, 1991a.

. Epistemology externalized. Dialectica, 45, 2-3, p. 191 202; reimpresso In: Subjective, intersubjective, objective. London: Clarendon Press, 1991b, p. 193-204.

. Externalisms. In: KOTAKTO, P.; PAGIN. P.; SEGAL, G. Interpreting Davidson. Stanford: CSLI, 2001.

FODOR, J. Psychosemantics. Cambridge: MIT Press, 1987.

KRIPKE, S. Wittgenstein on rules and private language. Oxford: Blackwell, 1982

McDOWELL, J. Criteria, defeasibility, and knowledge. In.: Meaning, knowledge and reality. Cambridge: Harvard University Press, 1998, p. 369-94. Press, 1994.

Mind and world. Cambridge: Harvard University 
Knowledge and the internal. Philosophy and Phenomenological Research, 55, p. 877-893, 1995.

McKINSEY, M. Anti-individualism and priviledged access. Analysis, 51, p. 9-16, 1991.

PINEDO GARCIA, M. ; BENSUSAN, H. Showing the inferentialist fly the way out of the bottleneck. apresentada na XV Spanish Philosophy and Cognitive Science Conference em discussão com R. Brandom, 2005.

PUTNAM, H. Realism and reason. In: Meaning and the moral sciences. London: Routledge, 1978.

The Meaning of 'Meaning'. In: Mind, language and reality (Philosophical Papers). V. 2. Cambridge: Cambridge University Press, 1975.

QUINE, W. V. O. Carnap and logical truth. Synthese, 12, p. 350-374, 1960.

RORTY, R. Pragmatism, Davidson and truth. In: LEPORE, Ernest (ed.). Truth and interpretation: perspectives on the philosophy of Donald Davidson. Cambridge: Blackwell, 1986, p. 333-355.

WITTGENSTEIN, L. On certainty. Trad. Denis Paul and G. E. M. Anscombe. Oxford: Basil Blackwell, 1969. 